This is the final peer-reviewed accepted manuscript of:

A. Borghetti, R. Bottura, M. Barbiroli and C. A. Nucci, "Synchrophasors-Based Distributed Secondary Voltage/VAR Control via Cellular Network" in IEEE Transactions on Smart Grid, vol. 8, no. 1, pp. 262-274, Jan. 2017

The final published version is available online at:

https://doi.org/10.1109/TSG.2016.2606885

Rights / License:

The terms and conditions for the reuse of this version of the manuscript are specified in the publishing policy. For all terms of use and more information see the publisher's website.

This item was downloaded from IRIS Università di Bologna (https://cris.unibo.it/)

When citing, please refer to the published version. 


\title{
Synchrophasors-based Distributed Secondary Voltage/VAR Control via Cellular Network
}

\author{
Alberto Borghetti, Fellow, IEEE, Riccardo Bottura, Marina Barbiroli, Carlo Alberto Nucci, Fellow, \\ IEEE
}

\begin{abstract}
The impact of the increasing connection of distributed generation to medium voltage (MV) feeders, with particular reference to photovoltaic (PV) units, justifies the investigation on secondary voltage/VAR control (VVC) schemes able to improve the utilization of available control resources and to reduce reactive power flows. The paper deals with a secondary VVC scheme based on a distributed multi-agent approach that requires only the estimation of the reactive power flows between the buses where the PV units with reactive power control capability are connected. Phasor Measurement Units (PMUs) are used to get the relevant information. In general, distributed control approaches are expected to work adequately even by using communication infrastructures with lower performances than those required by centralized approaches. The paper addresses such an issue by the analysis of the distributed VVC performance when a shared cellular network is used for the cooperative adjustment of $P V$ inverters reactive power outputs and of tap positions of transformers equipped with on-load tap changers. The analysis is carried out by using a specifically developed ICT (Information and Communications Technology)power co-simulation platform. It is shown that the VVC scheme has adequate performances also in the presence of significant levels of background traffic and data loss.
\end{abstract}

Index Terms - Multi-agent systems, photovoltaic power generation, power distribution network, phasor measurement unit, reactive power control, secondary voltage/var control, simulation.

\section{INTRODUCTION}

$\mathrm{N}$ ATIONAL and international standards define connection rules in order to limit the potentially harmful impact of distributed generation (DG) on the operation of the power distribution system, taking into account the strategies and type of equipment currently adopted in distribution network for voltage control and fault protection. It is well known that high penetration of photovoltaic (PV) generation can cause particular concerns (e.g. [1]). Therefore, as PV applications become more and more important and diffused, specific codes and standards are consequently updated [2]. For instances, recent standards in Germany (VDE-AR-N 4105) and Italy (CEI 0-16 and CEI 0-21), include requirements not only for

This work is supported in part by University of Bologna (FARB FFBO122030) and ENIACJU/CALL 2011-1/296131 E2SG "Energy to smart grid".

The authors are with the Dept. of Electrical, Electronic and Information Engineering, University of Bologna, I-40136 Bologna, Italy (e-mail: \{alberto.borghetti; riccardo.bottura2; marina.barbiroli; carloalberto.nucci\} @unibo.it). power curtailment, but also for voltage support and lowvoltage ride through (LVRT) capability, by exploiting the capability of commercially available PV inverters to regulate their reactive power output. Voltage support is achieved by reactive power injection strategies, whist the LVRT function avoids the loss of massive power production by PV units due to deep voltage sags and should be coordinated with the antiislanding function [3]

The decentralized and uncoordinated voltage control of DG units (e.g., by Q-V droop control loops) is possible, but may result in unequal share of reactive power compensation and significant reactive power flows in the network. In distribution networks, variations of the root mean square (RMS) voltage values are also significantly correlated to active power flows in addition to reactive power flows. Moreover, the local droop control cannot directly deal with the influence of reactive power injection and absorption into other parts of the system and it may interfere with the voltage regulation action of transformers equipped with on-load tap changers (OLTCs).

Therefore, several alternative approaches have been proposed in the literature for the coordinated adjustment of the reactive power injections provided by DG units in order to achieve an improved voltage/var control (VVC) in the distribution network: improved local control schemes (e.g., [4],[5]), centralized solution of an optimization problem (e.g. in [6]-[11] and references therein) also in a stochastic framework (as in, e.g., [12], [13]), or consensus and cooperation control schemes applied by using networked multi agent systems (MAS) (e.g. [14]-[21] and references therein).

Centralized approaches are usually based on a system state estimation that requires heavy communication infrastructures and that can be affected by both reliability issues and modelling errors. Moreover, an adequate redundancy is needed to compensate the uncertainty of the availability of measuring devices in order to determine the state estimation (for the case of state estimation based on phasors measurement units see, e.g., [22] and references therein). On the other hand, the implementation of cooperative or consensus approaches by means of a MAS can represent a more effective solution for the case of limited connectivity and/or communication bandwidth, since only the exchange of information between neighboring agents in this case is needed. Moreover, MAS are typically considered more robust, since they can continue to work even when one or more agents are unavailable, although with reduced performances.

This paper deals with a hierarchical approach that combines 
the primary voltage control provided by the decentralized controllers of DGs and OLTCs with a secondary VVC control layer that implements a gossip algorithm in a MAS approach. The implemented gossip algorithm is a consensus procedure, in which only two agents, located at neighboring nodes of the communication network, are active and exchange information at each control cycle, without the need of synchronizing actions. According to the literature (for a thorough review see [23]), the typical advantages of gossip algorithms are the use of minimal computation and communication resources and their robustness to changes in network topology and to timedelays. In particular, the gossip algorithm implemented in the secondary VVC procedure acts to compensate the reactive power flows in the network and therefore it is a good complement of the action of both Q-V droop control loops implemented in PV units and of the voltage control of OLTC transformers.

Within this context, the contributions of the paper are twofold. First, it is shown that the application of the Kron reduction technique simplifies the secondary VVC procedure, avoiding the need of a complete state estimation, i.e. the identification of all the power flows and bus voltages, as only the estimation of reactive power flows between the nodes relevant to the couple of active agents is required. Second, it is shown that the rules implemented in the secondary VVC procedure are able to efficiently coordinate their action with the local primary controls and to limit the negative effects of latency and data loss in the communication links. The analysis of these effects and the design of the specific countermeasures have been carried out by using a co-simulation platform developed at the authors laboratory in order to reproduce the detailed transient behavior of both the power system and the communication network.

Focusing on DG consisting of PV units, the secondary VVC approach dealt with in this paper is based on three main features:

1) the use of phasors measurement units (PMUs);

2) the adoption of a MAS approach that implements a secondary VVC scheme coordinated with the local voltage control of both PV inverters and of OLTCs;

3) the use of a shared communication network, with particular reference to a cellular network often adopted for the operation of MV systems.

Justifications for the adoption of the above features as well as the general characteristics of the proposed approach are provided in Section II.

Section III presents the coordination between the proposed MAS-based secondary VVC scheme with the local voltage controls of transformers equipped with on-load tap changers (OLTCs) and with the primary control of PV inverters, taking into account the relevant limits that dynamically vary according to the variation of the real power output set point determined by the maximum power point tracking (MPPT) algorithm.

Section IV describes the models implemented in a simulation platforms in order to assess the performances of the MAS-based VVC scheme taking into account the characteristics and limitations of the cellular communication network.

Section V presents the simulation analysis and Section VI concludes the paper.

\section{General Characteristic of the Adopted VVC APPROACH}

\section{A. Use of PMUs}

The use of PMUs is motivated by the growing interest to develop PMU-based applications also for distribution networks (the support of PMUs to transmission networks operation is already well established) so that PMUs are foreseen to be more commonly installed in future distribution equipment (see, e.g., [24] and references therein).

The most efficient reactive power compensation is the one that reduces reactive power flows in the branches of the network. Usually this objective is achieved by the allocation of the reactive power requested by the various loads to the nearest reactive power sources. This approach requires the collection of the measurements of all the reactive power requests or the adoption of an online state estimation procedure. In this paper, PMUs are used in order to provide an online estimate of the most convenient allocation of the reactive power requests among the available PV units. However, the cost issue is addressed by requiring the installation of the PMUs only at the buses where PV units and OLTC transformers are connected.

In order to better clarify this PMU-based approach, in the following we consider, as illustrative example, a single feeder between two sources, $G_{h}$ and $G_{k}$, located at the feeder terminations $h$ and $k$, and $N$ loads connected to as many internal nodes of the feeder.

It is in general acknowledged (e.g., [19]) that a typical efficient allocation of loads requests is proportional to the ratio between the distance (along the feeder) from the load to the other source and the distance between the two sources, i.e., the optimal source current injections at node $h$ and at node $k$ are

$$
I_{h}=\sum_{j=1}^{N} \frac{Z_{j k}}{Z_{h k}} I_{j} \text { and } I_{k}=\sum_{j=1}^{N} \frac{Z_{j h}}{Z_{h k}} I_{j},
$$

respectively, where $Z_{h k}$ is the longitudinal impedance of the entire feeder (by neglecting shunt admittances), whilst $Z_{j h}$ and $Z_{j k}$ are the longitudinal impedances between the node of the $j^{\text {th }}$ load, characterized by current phasor $I_{j}$, and the feeder terminations.

This allocation is in agreement with the result of the Kron reduction technique: the original $N+2$ node network is equivalent to a reduced $h-k$ branch and with the source current injections at node $h$ and at node $k$ augmented by the values of (1).

The proof follows. If the couple of nodes $k$ and $h$ is indicated with $\alpha$ and the set of $N$ internal nodes where loads are connected is indicated as $\beta$, the application of the Gaussian elimination to the relationship between column vector of node current phasors $\mathbf{I}$ and of voltage phasors $\mathbf{V}$ though admittance 
matrix $\mathbf{Y}$

$$
\left[\begin{array}{c}
\mathbf{I}_{\alpha} \\
\mathbf{I}_{\beta}
\end{array}\right]=\left[\begin{array}{cc}
\mathbf{Y}_{\alpha \alpha} & \mathbf{Y}_{\alpha \beta} \\
\mathbf{Y}_{\alpha \beta}^{T} & \mathbf{Y}_{\beta \beta}
\end{array}\right]\left[\begin{array}{c}
\mathbf{V}_{\alpha} \\
\mathbf{V}_{\beta}
\end{array}\right]
$$

gives

$$
\mathbf{I}_{\alpha}+\mathbf{Y}_{a c} \mathbf{I}_{\beta}=\mathbf{Y}_{r e d} \mathbf{V}_{\alpha}
$$

with

$$
\mathbf{Y}_{a c}=-\mathbf{Y}_{\alpha \beta} \mathbf{Y}_{\beta \beta}^{-1}
$$

and

$$
\mathbf{Y}_{\text {red }}=\mathbf{Y}_{\alpha \alpha}-\mathbf{Y}_{\alpha \beta} \mathbf{Y}_{\beta \beta}^{-1} \mathbf{Y}_{\alpha \beta}^{T} .
$$

For the case of the single $h-k$ branch:

$$
Y_{\text {red }}=\left[\begin{array}{cc}
1 & -1 \\
-1 & 1
\end{array}\right] Z_{h k}^{-1}
$$

and each element of matrix $\mathbf{Y}_{a c}$ is

$$
Y_{a c}(1, j)=\left(\frac{Z_{j k}}{Z_{h k}}\right)^{-1} \text { and } Y_{a c}(2, j)=\left(\frac{Z_{j h}}{Z_{h k}}\right)^{-1}, \forall j \in \beta
$$

that proves (1).

In this paper we assume that only the reactive power of the DG units could be adjusted by the secondary VVC, whilst their active power output is set by various technical and economic factors.

According to (3),

$$
\operatorname{Im}\left\{\mathbf{Y}_{r e d}^{*}\left|\mathbf{V}_{\alpha}\right|^{2}\right\}=\left[\begin{array}{l}
Q_{h k} \\
Q_{k h}
\end{array}\right]
$$

where the asterisk means complex conjugate, whilst $Q_{h k}$ and $Q_{k h}$ are the reactive power transfer in the $h-k$ branch at node $h$ and at node $k$ respectively. By assuming the positive direction of the reactive power transfer from $h$ to $k$, the reactive power flows from $h$ and $k, Q_{h k}^{\prime}$ and $Q^{\prime \prime}{ }_{h k}$, at both end of the branch are

$$
\begin{aligned}
Q_{h k}^{\prime} & =Q_{h k}=\frac{X_{h k}\left|V_{h}\right|^{2}}{\left|Z_{h k}\right|^{2}}-\frac{X_{h k}\left|V_{h}\right|\left|V_{k}\right|}{\left|Z_{h k}\right|^{2}} \cos \left(\theta_{h}-\theta_{k}\right) \\
& -\frac{R_{h k}\left|V_{h}\right|\left|V_{k}\right|}{\left|Z_{h k}\right|^{2}} \sin \left(\theta_{h}-\theta_{k}\right) \\
Q^{\prime \prime}{ }_{h k}= & -Q_{k h}=-\frac{X_{h k}\left|V_{k}\right|^{2}}{\left|Z_{h k}\right|^{2}}+\frac{X_{h k}\left|V_{h}\right|\left|V_{k}\right|}{\left|Z_{h k}\right|^{2}} \cos \left(\theta_{k}-\theta_{h}\right) \\
+ & \frac{R_{h k}\left|V_{h}\right|\left|V_{k}\right|}{\left|Z_{h k}\right|^{2}} \sin \left(\theta_{k}-\theta_{h}\right)
\end{aligned}
$$

where $\left|V_{h}\right|,\left|V_{k}\right|$ are the RMS values and $\theta_{h}, \theta_{k}$ are the phases of $V_{h}$ and $V_{k}$, respectively, whilst $Z_{h k}=R_{h k}+j X_{h k}$.

Now if values of phasors $V_{h}$ and $V_{k}$ are obtained by means of PMUs measurements and branch impedance $Z_{h k}$ is known, the optimal allocation of the reactive power between the DG units can be achieved by the compensation of the reactive power flows (9) and (10). This also helps in meeting the maximum current constraints in the feeder.

Equations (2), (3), (9), and (10) are valid for a network with any number of nodes, and they are not referring to a particular topology of the network, although the test networks analyzed in this paper have a radial configuration. Moreover, these equations could be directly used also for unbalanced feeders, by representing both lines and transformers with an equivalent network of uncoupled branches (as described in e.g., [25][29]).

\section{B. Adoption of a MAS Approach}

In a centralized approach, each DG unit is equipped with a PMU and it periodically sends the measured synchrophasors to a central Distribution Management System (DMS). The DMS calculates the reactive power injections of the DG units that compensates (9) and (10) after which it then sends the new set point values to the control systems of the involved DG units.

The continuous variation of the operating conditions and the topology of a distribution network makes particularly interesting the application of distributed control approaches in order to achieve systems which are more adaptive and resilient to the changing of the power supply/demand and to failures [30]. In particular a consensus mechanism between couples of decentralized controllers of a MAS appears to be well suited with the objective to compensate reactive power flows [17], [18]. In [31], [32] the gossip-like algorithm has been implemented in a ICT (Information and Communications Technology) - power co-simulation platform in order to evaluate the effects of the limitations of a wired communication network with a radial topology similar to the one of the power distribution feeder and to design appropriate countermeasures.

\section{Use of a Shared Cellular Communication Network and Co-simulation Platform}

Whilst in the previous papers, each couple of agents that control the DG units located at two different nodes, $h$ and $k$, tries to compensate the entire reactive power exchange between the two nodes, i.e. in (9) and (10) $Z_{h k}$ is the effective impedance between the node $h$ and node $k$, in this paper, as above described, the compensation $Z_{h k}$ is the impedance of the $h-k$ branch of the network obtained by applying the Kron reduction, i.e., each compensation acts in order to cancel the reactive power flow in that branch.

This approach appears to be advantageous when the communication network has not a radial topology as considered in the previous papers. In this paper the gossip-like algorithm is applied for the case of a MAS that uses a mobile cellular network characterized by a star-topology, taking into account that distribution system operators are currently using shared cellular networks more often than dedicated networks (as transmission system operators do). Since these networks may be affected by significant levels of latency and data loss, 
the associated negative effects on the performances of the proposed secondary VVC are analyzed by means of a cosimulation platform that implements a model of a third generation cellular network, namely a Universal Mobile Telecommunications System (UMTS), described in Section IV. The detailed model allows to take into account two different causes of latency and data loss: messages are queued due to system congestion and, if congestion exceeds a threshold, routers are forced to drop some packets; moreover, some packets can be lost due to the poor level of signal to interference and noise ratio (as a function also of the message length) [33].

\section{Multi-Agent Based Secondary VVC And COORDINATION WITH LOCAL PRIMARY CONTROLS}

We conceive the control system of the reactive power of each PV inverter, assumed to be three-phase and connected to a MV bus of the power distribution feeder through a transformer, as equipped with a UMTS communication module and with a phasor measurement unit (PMU). This networked control system is an agent of the MAS and it implements the following gossip-like algorithm for the secondary VVC.

\section{A. Gossip-like VVC algorithm}

At each control time step, the algorithm operates so that two PV units connected to different nodes of the power distribution systems change their reactive power outputs in a coordinate way in order to compensate the reactive power flow between them, i.e. each agent tries to supply the reactive power needed by the nearby loads.

More in detail, at each control cycle, a couple of agents, controlling two different PV units located at node $h$ and $k$, is activated by the previous active couple of agents. The two agents exchange the information relevant to both their bus voltage phasor measurements provided by their PMUs and reactive power margins $\delta_{h}^{\max }=Q_{h, \text { max }}-Q_{h}, \delta_{h}^{\min }=Q_{h, \text { min }}-Q_{h}$, $\delta_{k}^{\max }=Q_{k, \text { max }}-Q_{k}$ and $\delta_{k}^{\min }=Q_{k, \text { min }}-Q_{k}$, where $Q_{h}$ and $Q_{k}$ are the current set point values of their reactive power control systems, whilst $Q_{h, \text { min }}, Q_{h, \text { max }}$ and $Q_{k, \text { min }}, Q_{k, \text { max }}$ are the inverters operating limits. The two agents evaluate the reactive power flow $\overline{Q_{h k}}$ between them and adjust the reactive power output of their inverters in order to create a reactive power counterflow of the same magnitude. The value of $\overline{Q_{h k}}$ is estimated by using (9) and (10): if $Q^{\prime}{ }_{h k}$ and $Q^{\prime \prime}{ }_{h k}$ have different signs, then $\overline{Q_{h k}}=0$; otherwise, i.e. if the signs are the same, $\overline{Q_{h k}}=\min \left(\left|Q^{\prime}{ }_{h k}\right|,\left|Q^{\prime \prime}{ }_{h k}\right|\right) \cdot \operatorname{sgn}\left(Q_{h k}^{\prime}\right)$. The reactive power outputs of the inverters at node $h$ and node $k$ are adjusted by adding the values $\Delta Q_{h}=-\Delta Q$ and $\Delta Q_{k}=-\Delta Q$, respectively, where

$$
\Delta Q=\max \left(\min \left(\overline{Q_{h k}}, \delta_{k}^{\max },-\delta_{h}^{\min }\right), \delta_{k}^{\min },-\delta_{h}^{\max }\right) .
$$

Then, after a time delay equal to $t_{\text {wait, }}$ allowing the system to reach a new steady state condition, a different couple of agents is activated by the previous one. More in detail, as each agent knows the communication addresses of all the other agents, after the var compensation agent $h$ randomly choses new agent $h_{\text {new }}$ of the next couple of agents to be activated, by avoiding agent $k$ recently involved in the procedure if there is another available agent. Then, after $t_{\text {wait }}$ from the last compensation, new agent $h_{\text {new }}$ choses new agent $k_{\text {new. The new agents }}$ exchange the PMU values and margins $\delta^{\max }$ and $\delta^{\min }$ between them and apply (9), (10), and (11) in order to calculate the amount of the new compensation that is expected to produce a further decrease of the reactive power flows.

Time delay $t_{\text {wait }}$ is chosen equal to $1 \mathrm{~s}$ in the simulations of this paper. In general, for the simulation tests, the values of the time parameters are chosen lower than those that would be adopted in a real application, in order to better analyze the negative effects of the latency of the communication network on the performances of the VVC algorithm.

The successive compensation cycles are expected to decrease branch currents and therefore both power network losses and voltage drops.

As a countermeasure against communication latency, each agent is provided with a memory buffer where the PMU data with the relevant time tag $t_{\text {meas }}$ are stored so that reactive power flows are estimated by using synchronous values of voltage phasors. Moreover, a maximum communication round-trip delay $t_{\text {wait }}$ is defined, after which the procedure carries on with the choice of a new active agents.

In order to guarantee the persistence of the procedure also in the presence of packet losses, the algorithm allows the start of concurrent multiple var compensation processes. In order to limit the possible negative effects of unwanted and unsynchronized multiple compensation process, such a possibility is limited by the assignment of an increasing priority index to each process. Concurrent compensation processes with priority indexes lower than the others are progressively stopped by the agents.

As a countermeasure against the complete failure of a critical communication links, a spontaneous activation is allowed after a predefined long time (e.g., several minutes) in which an agent is never activated.

\section{B. Coordination between the Secondary VVC and the Primary Control Functions of PV Units and OLTCs}

The action of the secondary VVC is coordinated with the action of the primary control loops of the PV units and of the OLTCs. The coordination is accomplished by taking into account two aspects:

a) for the coordination with PV units, the variable reactive power margins available at the PV units due to the intermittent active power output;

b) for the coordination with OLTCs, the significant transients and wear associated with the operation of OLTCs.

It is worth adding that the action of the primary control of PVs is expected to be significantly faster than the action of the secondary VVC, yet it is useful that the action of the VVC would anticipate that of OLTCs in order to reduce the number 
of their maneuvers and to extend their expected life-span.

Regarding aspect a), the secondary VVC algorithm takes into account the limits of the PV inverters and it is coordinated with their faster local voltage control functions as described below.

Reactive power limits $Q_{\max , i}$ and $Q_{\min , i}$ of PV inverter $i$ are dynamically updated on the basis of the active power value $P_{i}$ determined by the MPPT algorithm, so that both maximum inverter current $I_{\max , i}$ and voltage $V_{\max , i}$ limitations are met (e.g. [34], [35]):

$$
\begin{aligned}
& Q_{\text {max }, i}, Q_{\min , i}= \pm \sqrt{\left(\left|V_{i}\right| I_{\max , i}\right)^{2}-P_{i}^{2}} \\
& Q_{\text {max }, i}=\sqrt{\left(\frac{\left|V_{i}\right| V_{\text {max }, i}}{X_{i}}\right)^{2}-P_{i}^{2}-\frac{\left|V_{i}\right|^{2}}{X_{i}}}
\end{aligned}
$$

where $X_{i}$ represents the total reactance of the transformer and grid filters used for the connection of inverter $i$ to the MV feeder if $\left|V_{i}\right|$ is the RMS voltage at the MV side of the transformer, whilst it represents the filter reactance if $\left|V_{i}\right|$ is measured at the filter output.

Each agent receives the information relevant to the changing of active power output of the PV unit by using local measurement. The $Q_{\max }$ value obtained by applying equation (12) is used in order to calculate margins $\delta^{\max }$ and $\delta^{\min }$, which, included in (11), guarantee that the capability limits of the involved couple of PV units will not be exceeded by the $\Delta Q$ variations assigned by the agents.

At each compensation cycle, the secondary VVC algorithm defines the reactive power set point $Q_{i}$ of the $i$-th PV inverter by adding $\Delta Q_{i}$, provided by (11), to the previous value. According to the typical Q-V droop loop control, we assume that the local voltage control function of the $i$-th inverter continuously adjusts the $Q_{i}$ value defined by the VVC by a quantity $\Delta Q_{\text {local }, i}$ if $\left|V_{i}\right|$ significantly differs from the rated value. $Q_{i}$ is decreased if $\left|V_{i}\right|>V^{+}$and it is increased if $\left|V_{i}\right|<V^{-}$:

$$
\begin{aligned}
& \Delta Q_{\text {local }, i}=-\left(\left|V_{i}\right|-V^{+}\right) \frac{\left(Q_{i}-Q_{\min }\right)}{\left(V_{\max }-V^{+}\right)} \text {if }\left|V_{i}\right|>V^{+} \\
& \Delta Q_{\text {local }, i}=\left(V^{-}-\left|V_{i}\right|\right) \frac{\left(Q_{\max }-Q_{i}\right)}{\left(V^{-}-V_{\min }\right)} \text { if }\left|V_{i}\right|<V^{-} \\
& \Delta Q_{\text {local }, i}=0 \quad \text { if }\left|V_{i}\right| \geq V^{-} \text {and }\left|V_{i}\right| \leq V^{+}
\end{aligned}
$$

where values $V^{+}, V$ are a few percent higher and lower than bus voltage rated value, respectively $(1 \pm 0.03 \mathrm{pu}$, in the simulations), whilst $V_{\max }$ and $V_{\min }$ in the denominators indicate the voltage deviations that cause a complete utilization of the available reactive power margins. In order to avoid oscillations, $\Delta Q_{\text {local }, i}$ is added to $Q_{i}$ through a transfer function (chosen with a time constant equal to 0.2 in the simulations of this paper) [5].

In order to coordinate the action of the secondary VVC with the primary control of PV units, each agent $i$ disregards the value provided by equation (11) by setting $\Delta Q_{i}=0$ if $\left|V_{i}\right|$ is outside the operating interval $\left(V^{-}, V^{+}\right)$and if the sign of $\Delta Q_{i}$ given by (11) is opposite of that of the reactive power correction $\Delta Q_{\text {local }, i}$ provided by (13).

Regarding aspect $b$ ), the assumed local control of OLTCs changes the tap when the RMS voltage value at the secondary side of the transformer differs from the reference value more than a predefined dead band $(0.015 \mathrm{pu}$ for at least $0.5 \mathrm{~s}$ in the simulations). In agreement with the usual OLTC control rules, the first tap change of each control action is postponed by a fixed delay (assumed equal to $20 \mathrm{~s}$ in the simulations for the HV/MV substation transformers and $10 \mathrm{~s}$ for the voltage regulators), whilst subsequent changes are applied after a delay time with an inverse law (in the simulations, the maximum delay is assumed to be $15 \mathrm{~s}$ for substation transformers and $10 \mathrm{~s}$ for voltage regulators). These intentional delays are added to the mechanical delay $(2 \mathrm{~s}$ in the simulations).

The coordination of the secondary VVC with the OLTC voltage control is achieved by associating a PMU-equipped agent of the MAS to the secondary side of the transformer. The agent participates to the regulation cycles of the secondary VVC procedure only by providing the phasor measurements for the evaluation of the reactive power flows, according to (9) and (10). Therefore each OLTC step change is readily taken into account in the following compensation cycles of the secondary VVC procedure.

In order to avoid unnecessary operations of the OLTCs of a series of cascaded transformers, the agent of the upstream OLTC sends a message to the agents of the downstream OLTCs when the voltage at the secondary side of the upstream transformer leaves the dead band. Such a message increases the tap delay of the downstream OLTCs (by $120 \mathrm{~s}$ in the simulations) if those actions are of the same type of the one that the upstream transformer is applying [36]. Once the upstream transformer terminates its action, after $t_{\text {wait }}$ its agent sends another message to the agents of downstream OLTCs in order to release their actions.

The coordination between the secondary VVC procedure and the OLTC controls in the case of multiple OLTCs transformers in the same feeder is achieved by splitting the set of agents in different groups. Each group is composed by the agents associated with the nodes without OLTC transformers in between. The groups perform independent VVC processes, i.e., at each compensation cycle, both agent $h$ and agent $k$ must belong to the same group.

\section{ICT-Power System Co-Simulation Platform}

The general architecture of the specifically developed ICTpower co-simulation platform has been described in [31], [32], [37]. It is based on the interface between the event-driven communication simulator Riverbed Modeler (formerly OPNET Modeler) and the time-driven power system simulation environment EMTP-RV. The synchronization 
mechanism between the two simulators is based on the typical waiting order of a communication through the use of the socket application programming interfaces (APIs). Simulation interval $\Delta t$ is defined by the integration time-step adopted in EMTP-RV (for this paper $\Delta t=1 \mathrm{~ms}$ ). As $\Delta t$ is very small with respect to the analyzed transients, it is negligible the inaccuracy due the time shift of all Riverbed events that happen within a $\Delta t$ interval to the end of the same interval.

This paper presents the results analysis of a distributed secondary VVC that uses an UMTS cellular network with the characteristics of those usually adopted by distribution system operators. The model of the UMTS network is described here below, together with a review of the models adopted for the power system components.

\section{A. UMTS Network Model}

The communication network model represents the three basic UMTS components: the user equipment (UE), i.e. the UMTS module of each agent, the UMTS Terrestrial Radio Access Network (UTRAN) and the Core Network (CN). UTRAN includes the Node B and the Radio Network Controller (RNC), which manages the Node B logical resources and also the UE-Node B interface resources. Each Node B controls the radio transmission and reception of a cell and performs the packet relay between $\mathrm{UE}$ and the corresponding $\mathrm{RNC}$ in the coverage area. $\mathrm{CN}$ contains the serving GPRS support node (SGSN) and the gateway GPRS support node (GGSN). SGSN maintains access controls, security functions and also keeps track of UE locations. The GGSN encapsulates the packets and routes them to the SGSN that are received from the external network or Internet.

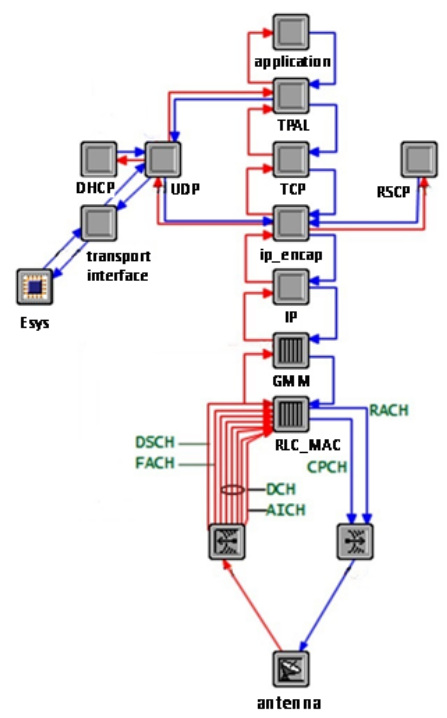

Fig. 1. Extended node model of UMTS UE. AICH: acquisition indicator channel; $\mathrm{CPCH}$ : common packet channel; $\mathrm{DCH}$ : dedicated channel; $\mathrm{DSCH}$ : downlink shared channel; RACH / FACH: random access channel / forward access channel; IP: internet protocol; TCP: transmission control protocol; UDP: user datagram protocol; DHCP: dynamic host configuration protocol; TPAL: transport adaptation layer; RSCP: received signal code power.

Fig. 1 shows the model of the UMTS UE. The GMM module (GPRS mobility/session management) manages GPRS attachment, packet data protocol (PDP) context establishment, service requests, and radio access bearer (RAB) activation and it handles the interface with the IP stack. The RLC_MAC module performs radio link control (RLC) and media access control (MAC) functionalities, both in UEs and router control planes. The node model is extended by an external system (Esys) module that enables the Riverbed interface with the EMTP simulation environment.

The air interface between each UE and the Node B is based on Wideband Code Division Multiple Access (W-CDMA) access scheme and uses a direct spread with a chip rate of 3.84 $\mathrm{MHz}$ and nominal bandwidth of $5 \mathrm{MHz}$. The model supports FDD (frequency division duplexing) duplex mode. The radio frame has a length of $10 \mathrm{~ms}$ and it is divided into 15 slots. Spreading factors vary from 256 to 4 for uplink and from 512 to 4 for downlink, which allow data rates of up to $2 \mathrm{Mbps}$. The model accounts for the channel block error rate (BLER) that is the percentage of transport blocks with errors over the total number of transport blocks. The communication channels between each Node B and RNC (and $\mathrm{CN}$ ) are assumed wired with large data rate.

The Riverbed model supports the UMTS four main types of quality of service (QoS): background, interactive, streaming and conversational. These attributes include the traffic class, maximum and guaranteed bit rates, delivery order, transfer delay, maximum size of the service data unit (SDU) and SDU error ratio. The UE RLC interface could operate in either unacknowledged mode (UM) or acknowledged mode (AM). Retransmission decreases the effects of the BLER but increases the communication delay.

In this paper, simulations of the VVC procedure are performed by assuming the adoption of the interactive QoS traffic class, which has higher priority than background, even if a minimum bit rate value is not guaranteed. We have chosen to operate in Acknowledge Mode (AM). The uplink and downlink dedicated signaling channels (DCHs) scheduling is adopted with the maximum bit rate of $64 \mathrm{kbps}$ (as a default value for the interactive QoS traffic class).

In order to test the robustness of the gossip-like procedure with respect to delays generated in the communication network, some simulations are performed with a background traffic (BT) due to the presence of additional UEs other than those associated with the agents. Traffic profiles available in Riverbed Modeler are adopted in order to represent the BT generated by both the new UEs and by the agents. Each user traffic profile is defined by a probability distribution function (PDF) that describes the experimental results collected in real networks in different scenarios, as reported in the 3GPP technical report TR 36.822. Also for the new UEs, an interactive QoS traffic class has been defined (the analysis of the scheduling effects of the QoS is out of the scope of this paper).

\section{B. Power Distribution Feeder Model}

The EMTP-RV model of the MV power feeder is mainly composed by the three-phase constant-parameters PI models for the representation of the unbalanced lines, the models of three-phase transformer with OLTCs (adapted from [38]), the models of the unbalanced voltage-dependent loads (constant 
impedance, constant current and constant active and reactive power) and the model of the PV units. The HV network is represented by an ideal positive sequence constant voltage generator.

The PMU of each agent is assumed to provide 10 estimates per second. The accuracy of PMUs is represented by the Normal distribution of the measurement errors of the prototype for MV applications described in [39]. In the simulations, the corresponding standard deviation values are assumed equal to $10.7 \mu \mathrm{rad}$ for phase error and $58.510^{-6} \mathrm{pu}$ for RMS error, respectively, taking into account also the expected accuracy the capacitive voltage dividers.

The PV units are represented by components able to inject assigned and adjustable three-phase active and reactive powers. As a first approximation of the quasi-steady-state behavior of power electronic interfaced sources, the PV model is composed by two positive-sequence triplets of current generators. The amplitude of one triplet is controlled by a feed-back regulator in order to inject the requested value of three-phase active power, whilst the phase angle between the injected current and bus voltage is regulated so to achieve a zero value of reactive power. The controls of the second triplets have a reverse function, i.e. amplitude is controlled in order to inject the requested reactive power and phase angle is controlled in order to cancel out active injection. Reference value $Q_{i}$ of the reactive power injection is dynamically changed by the associated networked agent and by the local voltage regulator taking into account the variable $Q_{\max }$ and $Q_{\min }$ limits, as described in Section III. A smooth transition between different power levels in a short time window of few hundreds of milliseconds is represented.

\section{Simulation Results}

We present here the numerical results obtained for two test cases illustrated in Fig. 2 (indicated as TF 1) and Fig. 3 (TF2).

TF1: IEEE 37-node Test Feeder [40] with 6 PV units (each equipped with a three-phase $500 \mathrm{kVA}$ inverter) connected to nodes 702, 712, 706, 703, 708 and 711, respectively (red dots in Fig. 2), and with an OLTC transformer at the substation (the secondary side node is 701 indicated with a blue dot in Fig. 2), with \pm 8 tap increments of $1.875 \%$ Two Node B are needed to guarantee the coverage (the two cells include the UEs at nodes 701, 702, 712 and 706,703,708,711, respectively).

TF2: IEEE 123-node Test Feeder [40], with 5 PV units (each equipped with a three-phase $500 \mathrm{kVA}$ inverter) connected to nodes $13,28,47,87$, and 108 , respectively, and with two OLTC transformers: OLTC1 with \pm 8 tap increments of $1.875 \%$ at the substation transformer (the secondary side of which is node 149) and OLTC2 with \pm 16 tap increments of $0.625 \%$ for the voltage regulator with node 67 at the secondary side. The two sets of agents are those relevant to nodes $\{149,13,28,47\}$ and $\{67,87,108\}$, respectively.

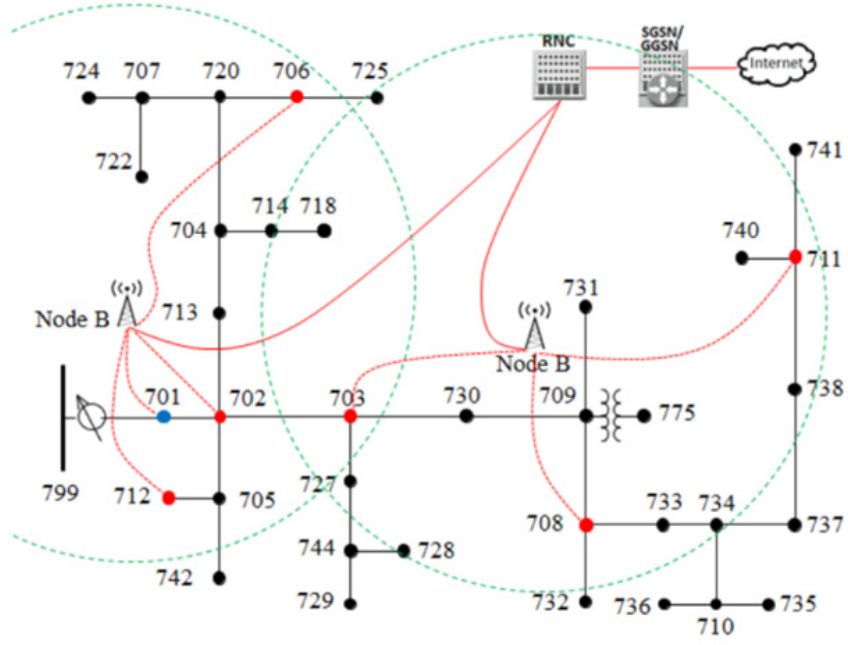

Fig. 2. TF1: one-line diagram of power feeder (in black) and UMTS communication network (dotted red lines represent wireless channels, solid red lines represent wired channels). The dots represent 7 networked controllers (agents). The green circles indicate the estimated coverage areas of the Node B antennas.

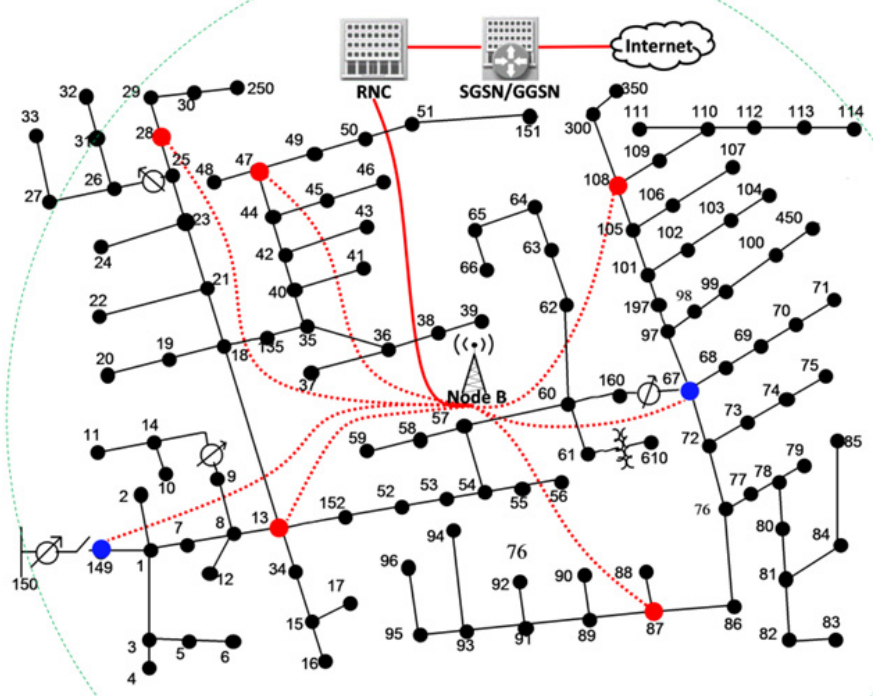

Fig. 3 TF2: one-line diagram of power feeder, UMTS communication network and location of the agents.

The procedure has been applied to a constant normal load condition, as defined in [40], and to a higher load level. For illustrative purposes, the high load condition has been obtained by multiplying both the active and reactive power normal values at each load node by a different coefficient (obtained as a uniformly-generated random number between 1.3 and 1.7). The initial reactive outputs of all the PV units are null. The OLTCs start in tap position 0. In the initial conditions, for the case of normal load level the network loss values are equal to $25,4 \mathrm{~kW}$ for TF1 and $40,4 \mathrm{~kW}$ for TF2, for the case of high load level the loss values are $59,6 \mathrm{~kW}$ for TF1 and $149,8 \mathrm{~kW}$ for TF2.

For the estimation of the reactive power exchanges $Q^{\prime}{ }_{h k}$ and $Q "{ }_{h k}$ by means of (9) and (10), each agent $h$ knows the value of impedances $Z_{h k}$ connecting node $h$ to every other node $k$ of the reduced network, other than the voltage synchrophasors assumed to be measured at the MV nodes in 
the simulations. The values of $Z_{h k}$ are provided by (5). The results of this Section have been obtained by using a positive sequence admittance matrix $\mathbf{Y}$ calculated by averaging the diagonal and off-diagonal values of the impedances matrices of unbalanced lines and by neglecting shunt capacitances. Very similar results have been obtained by representing both lines and transformers with an equivalent network of uncoupled branches (as done in [29] for the case of a mixed integer linear programming approach) and, for each PV inverter, by averaging the reactive power set points of the three phases.

The simulation results are grouped in two subsections.

Subsection V.B presents simulation results obtained assuming the communication network in ideal conditions, with the aim at illustrating the effectiveness of the secondary VVC scheme also in presence of a fast variation of the PV active power output production due to a cloud passage.

Subsection V.B presents the analysis of the effects of latency and data loss in the cellular communication network on the performances of the distributed secondary VVC procedure. This analysis is the main motivation of the use of the co-simulation platform described in Section IV.

\section{A. Illustrative Examples of the Effectiveness of the Secondary $V V C$}

The simulation results are obtained by assuming the communication network in ideal conditions (i.e., without additional back ground traffic produced by the agents and without data loss), the normal load level and the primary controls of both PV units and OLTC transformers always active.

Fig. 4 and Fig. 5 shows the results obtained for TF1 with the active power output of all PV units constant and equal to $400 \mathrm{~kW}$. These figures compare the results obtained by assuming the secondary VVC procedure active and without it. In order to better illustrate the coordination between the secondary VVC action with the primary voltage controls of PV units and OLTCs, two slightly different versions of the secondary VVC algorithm are used:

1) if voltage $\left|V_{i}\right|$ measured by agent $i$ is lower than $0.97 \mathrm{pu}$ or higher than $1.03 \mathrm{pu}$ then the VVC algorithm does not modify the PV reactive power output (i.e., sets $\Delta Q_{i}$ equal

to 0$)$ only if the sign of $\Delta Q_{i}$ given by (11) would be opposite than that of reactive power correction $\Delta Q_{\text {local }, i}$ provided by the local voltage control of the PV unit;

2) the secondary VVC action is also blocked if both agents involved in the compensation cycle measure voltages lower than $0.97 \mathrm{pu}$ or higher than $1.03 \mathrm{pu}$.

As in initial conditions, several voltage values of the nodes where PV are located are lower than $0.97 \mathrm{pu}$, the action of VVC (2) is delayed until the first tap change at the substation transformer at $22 \mathrm{~s}$ to position -1 . Without secondary VVC, the OLTC operates a second tap change to -2 at $44 \mathrm{~s}$.

Fig. 4 shows that the action of both the secondary VVC procedures allow a $62.6 \%$ reduction of the network power loss to $9.5 \mathrm{~kW}$. This result match the power loss reduction obtained by solving the centralized VVC optimization problem by using the mixed integer linear programming approach presented in [29]. Without the action of the secondary VVC, the power loss initially decreases to $18.4 \mathrm{~kW}$ because of the action of the primary control of the PV units but it increases again after the after the OLTC operations to almost the same initial value $(25.1 \mathrm{~kW})$.

Fig. 5 shows that, with the secondary VVC procedures, the final values of the bus voltages at the PV buses are significantly improved with respect to the initial conditions even without the second tap change at the substation transformer. The figure show only the voltage curves at bus 701 and bus 711 since the voltages at the other PV buses stay between these curves.

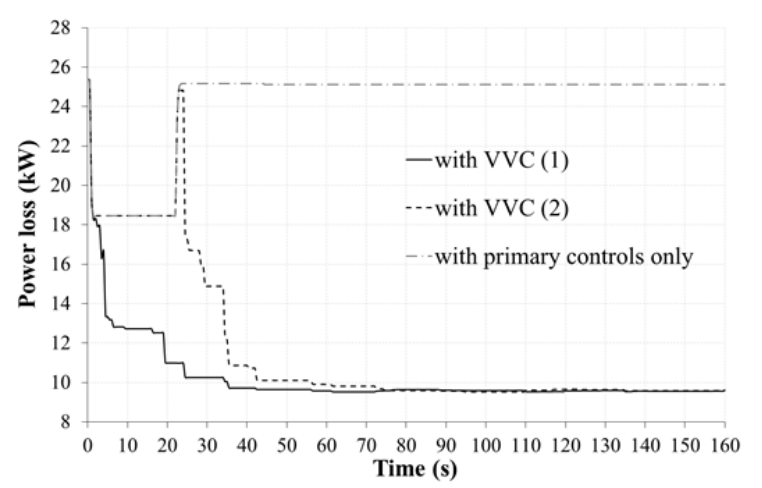

Fig. 4. Power loss variation in TF1 with and without secondary VVC.

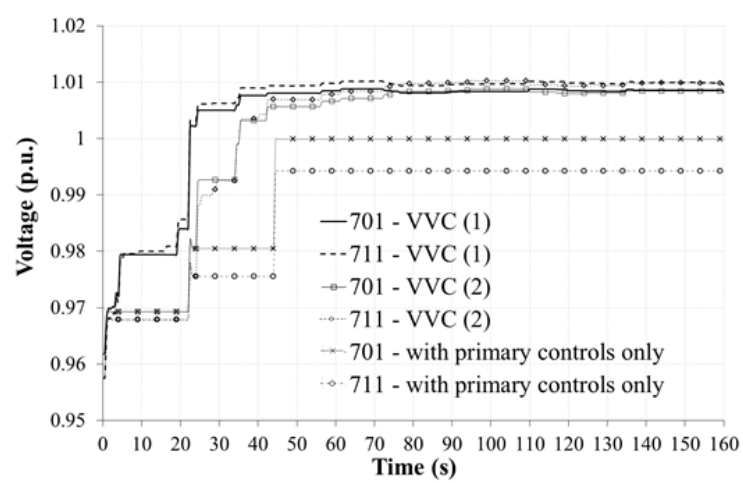

Fig. 5. Voltage variations at bus 701 and bus 711 of TF1 with and without secondary VVC.

Fig. 6 and Fig. 7 show the analogous results obtained for TF2. Sa shown by Fig. 6, a $13.6 \%$ power loss reduction to $34.9 \mathrm{~kW}$ is obtained with the secondary VVC (also in this case the value is in close agreement with the one obtained by using the optimization model of [29]), whilst without VVC the network power loss is slightly higher $(43.6 \mathrm{~kW})$ than the initial value due to the increase of voltages that, in turn, causes an increase of load power consumption. As shown by Fig. 7, OLTC1 operates at $22 \mathrm{~s}$ reaching tap position -1 . Without VVC OLTC2 operates 3 times (at $25 \mathrm{~s}, 33 \mathrm{~s}$, and $45 \mathrm{~s}$ ) reaching the final position -3 , whilst VVC limits the number of tap changes to only one (at $25 \mathrm{~s}$ ). 


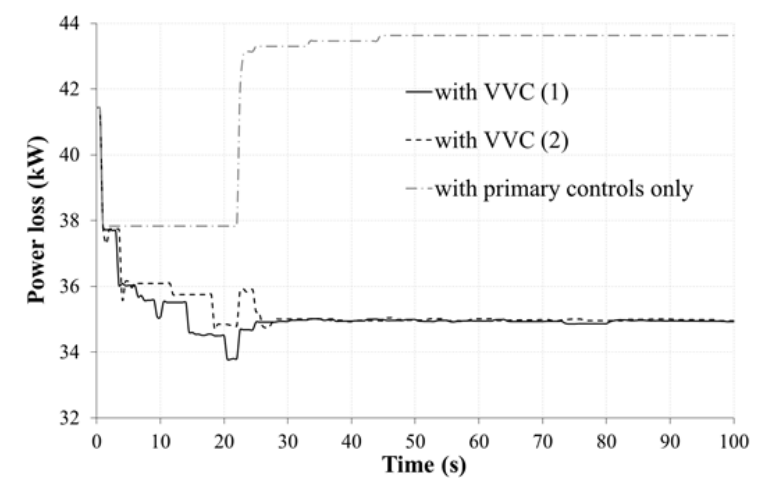

Fig. 6. Power loss variation in TF2 with and without secondary VVC.

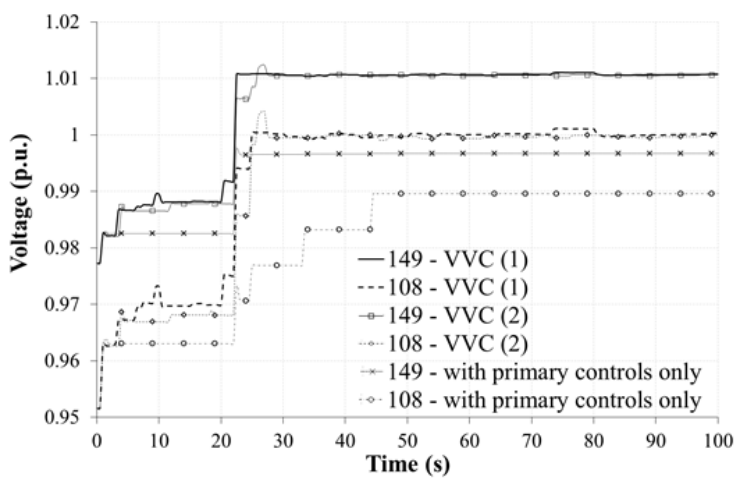

Fig. 7. Voltage variations at bus 149 and bus 108 of TF2 with and without secondary VVC.

The secondary VVC procedure is quite robust against transient power output variations of the PV units. This conclusion has been verified by using different profiles of the $\mathrm{PV}$ power output and by varying the PV units that experience the output variation. As an illustrative example the following in figures show the action of the secondary VVC procedure in case of the PV output power variation of Fig. 8, which has been derived from an available measurement during a cloud passage. Fig. 9 and Fig. 10 refer to TF1, in which the PV units connected to buses 202,703 , and 708 experience the power output variation of Fig. 8. Fig. 11 and Fig. 12 refer to TF2 and the PV units that experience the cloud passage are those connected to buses 28 and 47 . In both TF1 and TF2, the secondary VVC procedure is able to reach almost the same reduction of the network loss and the same voltage control as in the case without output power variations.

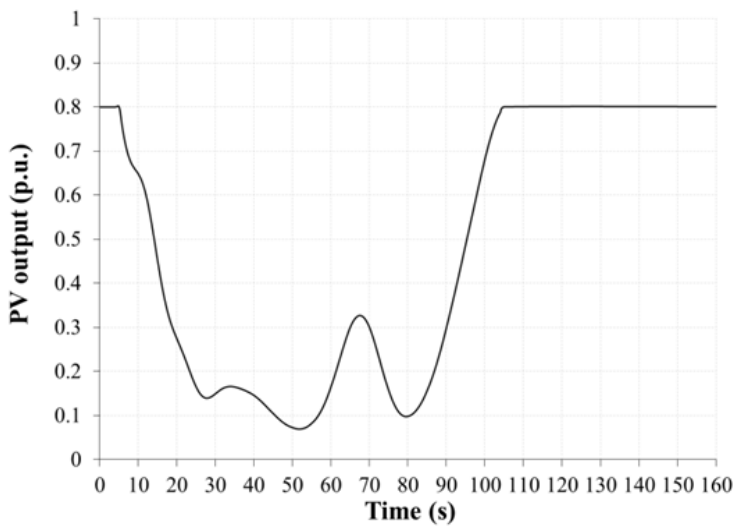

Fig. 8. Variable power output profile of PVs.

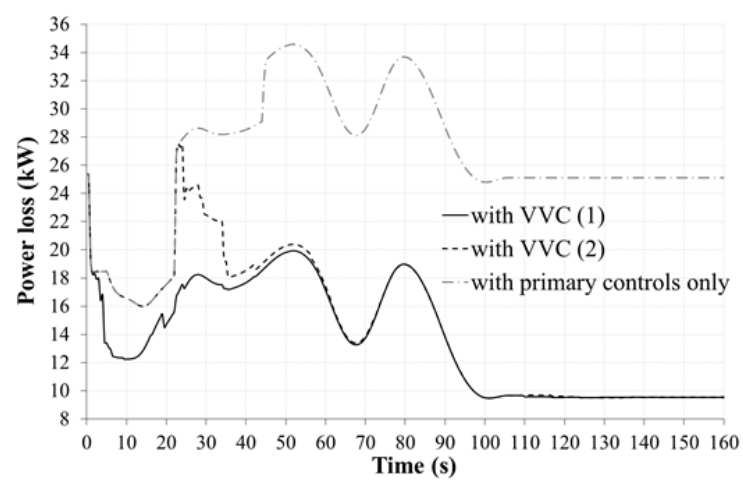

Fig. 9. Power loss variation in TF1 with and without secondary VVC.

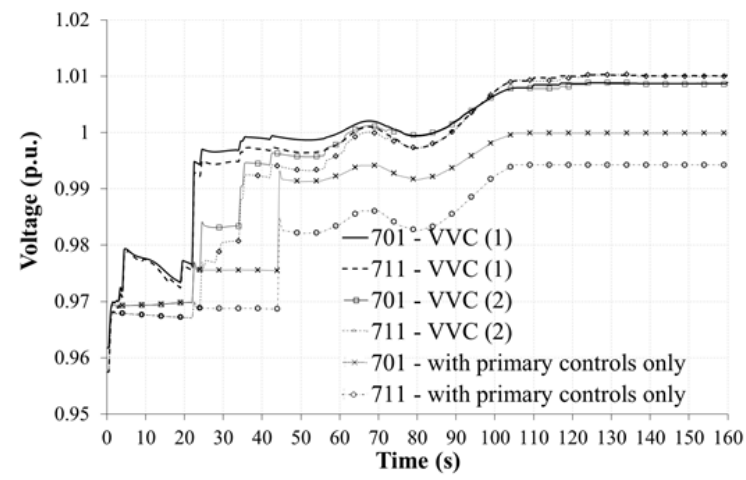

Fig. 10. Voltage variations at bus 701 and bus 711 of TF1 with and without secondary VVC.

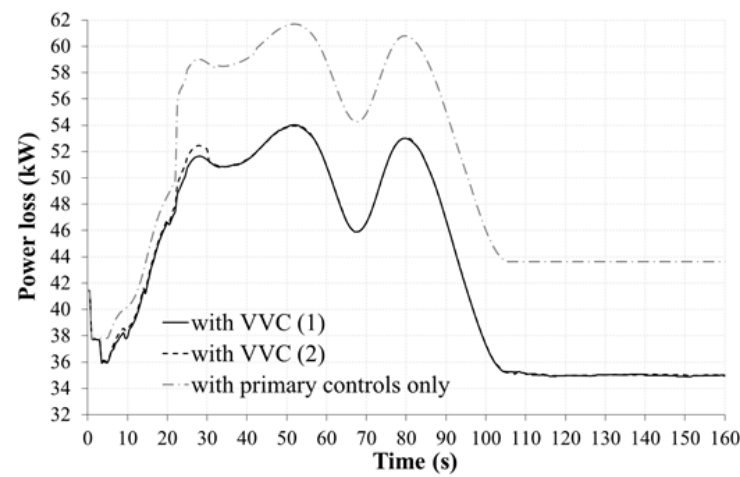

Fig. 11. Power loss variation in TF2 with and without secondary VVC.

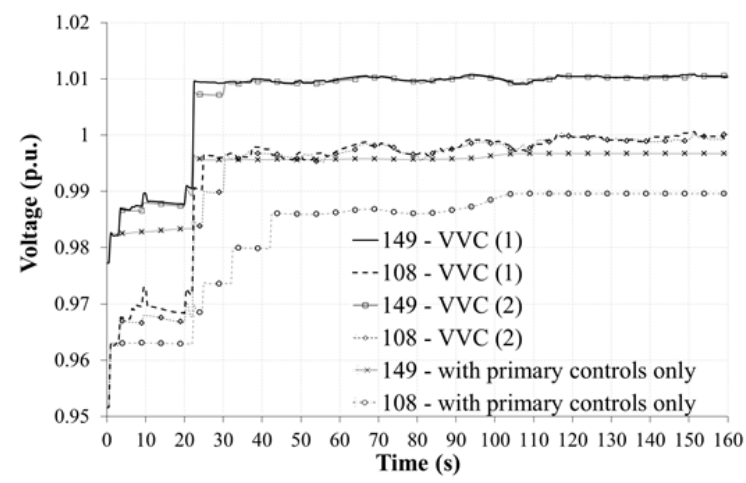

Fig. 12. Voltage variations at bus 149 and bus 108 of TF2 with and without secondary VVC.

The results of this section show that the gossip algorithm implemented in the secondary VVC procedure complements the action of both Q-V drop control loops of PV units and of the voltage control of OLTC transformers. Whilst the primary 
controls are focused on limiting significant variation of the local bus voltage, the secondary VVC acts to compensate the reactive power flows in the network, which results, for the examined cases, in a significant reduction of the network losses and in an improvement of the voltage profile.

\section{B. Analysis of the effects of latency and data loss}

The simulations are repeated for two different BLER values: $1 \mathrm{E}^{-5}$ (case indicated as BLER0) and 0.1 (BLER1), which is a typical reference performance (e.g. [41]).

Moreover, the simulations are repeated with BT (case indicated as BT1) and without the BT (BT0). In order to obtain a significant value of the BT the UEs associated to the agents and 6 additional UEs are forced to generate the BT towards 2 additional UEs receivers belonging to the same RNC subnetwork. The models adopted for the mobile users application are characterized by two different gamma distributions of the inter-arrival packet time in $\mathrm{s}$ (with parameters $0.0068,5$ and $0.2,0.5$, respectively) and exponential distributions of packet size in bytes (with parameters 41.03 and 62.97, respectively).

The results obtained for the 8 scenarios characterized by different values of BLER, BT and load levels are compared in Table I and Table II. Version VVC (2) of the algorithm is adopted. The tables report the results (mean value and standard deviation) of the statistical analysis carried out by performing 20 simulations for the same case. For each simulation, the pseudorandom number generator used for the choice of the active agents is initialized by a different seed state associated with the computer system time.

TABLE I

NUMBER OF COMPENSATION CYCLES, POWER LOSS DECREASE AND SETTLING

\begin{tabular}{|c|c|c|c|c|c|c|c|c|}
\hline \multicolumn{9}{|c|}{ TIME FOR TF1 AND TF2 } \\
\hline \multirow{2}{*}{$\begin{array}{l}\text { BLER } \\
\text { BT } \\
\text { (load } \\
\text { level) }\end{array}$} & \multicolumn{2}{|c|}{$\begin{array}{c}\mathbf{N}^{0} \text { of } \\
\text { compensation } \\
\text { cycles in 200s } \\
\text { mean (stdev) } \\
\end{array}$} & \multicolumn{2}{|c|}{$\begin{array}{c}\% \text { of } \\
\text { incomplete } \\
\text { compensations } \\
\text { mean (stdev) }\end{array}$} & \multicolumn{2}{|c|}{$\begin{array}{l}\text { Power loss } \\
\text { decrease (kW) } \\
\text { mean (stdev) }\end{array}$} & \multicolumn{2}{|c|}{$\begin{array}{l}\text { Settling time (s) } \\
\text { mean (stdev) }\end{array}$} \\
\hline & TF1 & TF2 & TF1 & TF2 & TF1 & TF2 & TF1 & TF2 \\
\hline $\begin{array}{l}\text { BLER0 } \\
\text { BT0 } \\
\text { (normal) }\end{array}$ & 154 & 154 & 0 & 0 & $\begin{array}{l}15.8 \\
(0.1)\end{array}$ & $\begin{array}{c}5.5 \\
(0.1)\end{array}$ & $\begin{array}{c}62.4 \\
(12.6)\end{array}$ & $\begin{array}{l}31.5 \\
(6.9)\end{array}$ \\
\hline $\begin{array}{l}\text { BLER1 } \\
\text { BT0 } \\
\text { (normal) }\end{array}$ & $\begin{array}{l}117.5 \\
(32.5)\end{array}$ & $\begin{array}{l}117.2 \\
(24.2)\end{array}$ & $\begin{array}{l}15.5 \\
(3.2)\end{array}$ & $\begin{array}{l}16.6 \\
(4.0)\end{array}$ & $\begin{array}{l}15.3 \\
(1.4)\end{array}$ & $\begin{array}{c}5.5 \\
(0.1)\end{array}$ & $\begin{array}{c}63.0 \\
(17.0)\end{array}$ & $\begin{array}{c}40.4 \\
(11.8)\end{array}$ \\
\hline $\begin{array}{l}\text { BLER0 } \\
\text { BT1 } \\
\text { (normal) }\end{array}$ & $\begin{array}{l}119.5 \\
(19.5)\end{array}$ & $\begin{array}{l}122.9 \\
(14.2)\end{array}$ & $\begin{array}{l}16.0 \\
(4.3)\end{array}$ & $\begin{array}{l}11.6 \\
(2.3)\end{array}$ & $\begin{array}{l}15.3 \\
(1.2)\end{array}$ & $\begin{array}{c}5.4 \\
(0.2)\end{array}$ & $\begin{array}{l}71.0 \\
(20.8)\end{array}$ & $\begin{array}{c}43.6 \\
(15.9)\end{array}$ \\
\hline $\begin{array}{l}\text { BLER1 } \\
\text { BT1 } \\
\text { (normal) }\end{array}$ & $\begin{array}{l}102.0 \\
(18.9)\end{array}$ & $\begin{array}{l}107.0 \\
(15.1)\end{array}$ & $\begin{array}{l}29.9 \\
(5.0)\end{array}$ & $\begin{array}{l}26.6 \\
(5.4)\end{array}$ & $\begin{array}{l}15.5 \\
(0.9)\end{array}$ & $\begin{array}{c}5.4 \\
(0.5)\end{array}$ & $\begin{array}{c}77.5 \\
(20.3)\end{array}$ & $\begin{array}{c}42.6 \\
(18.0)\end{array}$ \\
\hline $\begin{array}{l}\text { BLER0 } \\
\text { BT0 } \\
\text { (high) }\end{array}$ & 154 & 154 & 0 & 0 & $\begin{array}{c}25.6 \\
(0.05)\end{array}$ & $\begin{array}{l}19.4 \\
(0.5)\end{array}$ & $\begin{array}{c}78.3 \\
(11.5)\end{array}$ & $\begin{array}{c}93.9 \\
(36.4)\end{array}$ \\
\hline $\begin{array}{l}\text { BLER1 } \\
\text { BT0 } \\
\text { (high) }\end{array}$ & $\begin{array}{l}129.3 \\
(12.6)\end{array}$ & $\begin{array}{l}115.9 \\
(30.7)\end{array}$ & $\begin{array}{l}17.6 \\
(3.3)\end{array}$ & $\begin{array}{l}16.3 \\
(2.8)\end{array}$ & $\begin{array}{l}25.5 \\
(0.9)\end{array}$ & $\begin{array}{l}18.0 \\
(3.4)\end{array}$ & $\begin{array}{l}102.2 \\
(29.8)\end{array}$ & $\begin{array}{c}91.2 \\
(27.0)\end{array}$ \\
\hline $\begin{array}{l}\text { BLER0 } \\
\text { BT1 } \\
\text { (high) }\end{array}$ & $\begin{array}{l}119.9 \\
(18.8)\end{array}$ & $\begin{array}{l}121.0 \\
(23.1)\end{array}$ & $\begin{array}{l}16.4 \\
(3.9)\end{array}$ & $\begin{array}{l}11.0 \\
(3.3)\end{array}$ & $\begin{array}{l}25.0 \\
(2.3)\end{array}$ & $\begin{array}{l}18.5 \\
(3.3)\end{array}$ & $\begin{array}{c}87.7 \\
(16.3)\end{array}$ & $\begin{array}{c}79.2 \\
(17.5)\end{array}$ \\
\hline $\begin{array}{l}\text { BLER1 } \\
\text { BT1 } \\
\text { (high) }\end{array}$ & $\begin{array}{l}101.4 \\
(22.3)\end{array}$ & $\begin{array}{l}108.3 \\
(11.2)\end{array}$ & $\begin{array}{l}32.4 \\
(7.2)\end{array}$ & $\begin{array}{l}25.6 \\
(4.9)\end{array}$ & $\begin{array}{l}24.3 \\
(3.8)\end{array}$ & $\begin{array}{l}17.9 \\
(1.4)\end{array}$ & $\begin{array}{l}105.2 \\
(39.2)\end{array}$ & $\begin{array}{l}122.2 \\
(21.2)\end{array}$ \\
\hline
\end{tabular}

In Table I, the number of var compensation cycles denotes the number of compensation between a couple of agents during a $200 \mathrm{~s}$ simulation in which at least one PV inverter changes its reactive power output and the percentage of incomplete compensations indicates the percentage of cycles that do not complete regularly; the power loss decrease is the difference between power losses at the starting time and at $t_{\text {set }}$ (time for the power loss value to enter and remain within a $500 \mathrm{~W}$ band for at least $30 \mathrm{~s}$ ). In Table II, the numbers of packets (transmitted and received, if the relevant numbers differ) take into account only those packets carrying data relevant to the gossip algorithm; the percentage of ignored or lost packets refers to those that arrive at destination after $t_{\text {wait }}$ or do not arrive at all; packets delay indicates the travelling time of the packets that regularly arrive at destination before $t_{\text {wait }}$; the number of stopped process counts the stops of concurrent gossip processes due to the priority index.

TABLE II

NUMBER OF PACKETS (TX: TRANSMITTED, RX: RECEIVED), PACKET DELAY AND NUMBER OF STOPPED PROCESS FOR TF1 AND TF2

\begin{tabular}{|c|c|c|c|c|c|c|c|c|c|c|}
\hline \multirow[t]{2}{*}{$\begin{array}{l}\text { BLER } \\
\text { BT } \\
\text { (load } \\
\text { level) }\end{array}$} & \multicolumn{2}{|c|}{$\begin{array}{c}\mathbf{N}^{\mathbf{0}} \text { of } \\
\text { packets } \\
\text { mean (stdev) } \mathbf{T x} \\
\text { mean (stdev) Rx }\end{array}$} & \multicolumn{2}{|c|}{$\begin{array}{c}\text { \% of } \\
\text { packets } \\
\text { ignored } \\
\text { mean } \\
\text { (stdev) }\end{array}$} & \multicolumn{2}{|c|}{ 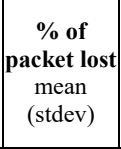 } & \multicolumn{2}{|c|}{$\begin{array}{c}\text { Packet delay } \\
\text { (ms) } \\
\text { mean (stdev) }\end{array}$} & \multicolumn{2}{|c|}{ 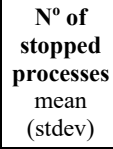 } \\
\hline & TF1 & TF2 & TF1 & TF2 & TF1 & TF2 & TF1 & TF2 & TF1 & TF2 \\
\hline $\begin{array}{l}\text { BLER0 } \\
\text { BT0 } \\
\text { (normal) }\end{array}$ & $\begin{array}{l}618.2(1.3) \\
618.2(1.3)\end{array}$ & $\begin{array}{l}618.8(1.4) \\
618.8(1.4)\end{array}$ & 0 & 0 & 0 & 0 & $\begin{array}{l}145.2 \\
(10.2)\end{array}$ & $\begin{array}{l}145.0 \\
(10.1)\end{array}$ & 0 & 0 \\
\hline $\begin{array}{l}\text { BLER1 } \\
\text { BT0 } \\
\text { (normal) }\end{array}$ & \begin{tabular}{|l|}
$542.6(125.8)$ \\
$447.3(104.8)$ \\
\end{tabular} & \begin{tabular}{|c|}
$526.5(104.4)$ \\
$434.6(87.0)$
\end{tabular} & \begin{tabular}{|c|}
5.5 \\
$(1.2)$
\end{tabular} & $\begin{array}{c}6.0 \\
(1.0)\end{array}$ & $\left|\begin{array}{r}11.9 \\
(5.7)\end{array}\right|$ & $\begin{array}{l}11.5 \\
(1.5)\end{array}$ & \begin{tabular}{|l|}
147.2 \\
$(32.7)$
\end{tabular} & $\begin{array}{l}146.2 \\
(29.6)\end{array}$ & $\begin{array}{l}11.1 \\
(3.4)\end{array}$ & $\begin{array}{l}11.1 \\
(3.6)\end{array}$ \\
\hline $\begin{array}{l}\text { BLER0 } \\
\text { BT1 } \\
\text { (normal) }\end{array}$ & $\begin{array}{l}528.2(77.5) \\
443.9(68.7) \\
\end{array}$ & $\begin{array}{l}551.7(52.7) \\
478.2(50.6)\end{array}$ & $\begin{array}{c}7.6 \\
(1.3)\end{array}$ & \begin{tabular}{c|}
6.3 \\
$(1.1)$ \\
\end{tabular} & $\begin{array}{c}8.5 \\
(1.3)\end{array}$ & $\begin{array}{c}7.2 \\
(1.0)\end{array}$ & $\left|\begin{array}{c}212.0 \\
(154.1)\end{array}\right|$ & $\begin{array}{c}239.3 \\
(173.5)\end{array}$ & \begin{tabular}{|c|}
7.0 \\
$(2.6)$
\end{tabular} & \begin{tabular}{|c}
7.4 \\
$(2.7)$
\end{tabular} \\
\hline $\begin{array}{l}\text { BLER1 } \\
\text { BT1 } \\
\text { (normal) }\end{array}$ & $\begin{array}{c}527(91.0) \\
371.6(62.6) \\
\end{array}$ & $\begin{array}{l}510.1(68.7) \\
378.4(55.3)\end{array}$ & $\begin{array}{l}13.0 \\
(1.4)\end{array}$ & $\mid \begin{array}{l}12.2 \\
(1.8)\end{array}$ & $\begin{array}{l}16.2 \\
(4.2)\end{array} \mid$ & $\begin{array}{l}13.8 \\
(1.7)\end{array}$ & $\left|\begin{array}{c}244.6 \\
(197.8)\end{array}\right|$ & $\begin{array}{c}259.0 \\
(202.3)\end{array}$ & $\begin{array}{l}13.0 \\
(5.3)\end{array}$ & \begin{tabular}{|c|}
9.6 \\
$(3.0)$
\end{tabular} \\
\hline $\begin{array}{l}\text { BLER0 } \\
\text { BT0 } \\
\text { (high) }\end{array}$ & $\begin{array}{l}618.5(1.3) \\
618.5(1.3)\end{array}$ & $\begin{array}{l}618.4(1.5) \\
618.4(1.5)\end{array}$ & 0 & 0 & 0 & 0 & $\begin{array}{l}145.1 \\
(10.1)\end{array}$ & $\begin{array}{l}145.4 \\
(10.4)\end{array}$ & 0 & 0 \\
\hline $\begin{array}{l}\text { BLER1 } \\
\text { BT0 } \\
\text { (high) }\end{array}$ & $\begin{array}{l}569.9(56.6) \\
474.5(30.5)\end{array}$ & $\begin{array}{l}520.0(139.1) \\
433.1(116.1)\end{array}$ & \begin{tabular}{|c|}
5.3 \\
$(0.7)$ \\
\end{tabular} & \begin{tabular}{|c|}
5.7 \\
$(1.0)$
\end{tabular} & $\begin{array}{l}11.5 \\
(1.7)\end{array}$ & $\begin{array}{l}10.9 \\
(1.3)\end{array}$ & \begin{tabular}{|l|}
146.2 \\
$(26.4)$
\end{tabular} & $\begin{array}{l}147.0 \\
(31.3)\end{array}$ & $\begin{array}{l}11.5 \\
(3.4)\end{array}$ & $\begin{array}{l}11.5 \\
(4.0)\end{array}$ \\
\hline $\begin{array}{l}\text { BLER0 } \\
\text { BT1 } \\
\text { (high) }\end{array}$ & $\begin{array}{l}548.6(49.1) \\
457.3(43.4)\end{array}$ & $\begin{array}{c}543.5(102.9) \\
472.6(92.0)\end{array}$ & \begin{tabular}{|c|}
7.2 \\
$(1.3)$ \\
\end{tabular} & $\mid \begin{array}{c}6.1 \\
(1.3)\end{array}$ & $\left|\begin{array}{c}9.3 \\
(5.8)\end{array}\right|$ & \begin{tabular}{|c|}
7.3 \\
$(1.3)$
\end{tabular} & $\left|\begin{array}{c}213.0 \\
(157.0)\end{array}\right|$ & \begin{tabular}{|c|}
239.0 \\
$(173.6)$
\end{tabular} & $\begin{array}{c}6.9 \\
(2.9)\end{array}$ & \begin{tabular}{|l}
7.9 \\
$(2.8)$
\end{tabular} \\
\hline $\begin{array}{l}\text { BLER1 } \\
\text { BT1 } \\
\text { (high) }\end{array}$ & $\begin{array}{c}488.7(104.7) \\
347.5(75.0)\end{array}$ & $\begin{array}{l}524.2(37.3) \\
389.6(36.5)\end{array}$ & $\begin{array}{l}13.4 \\
(2.3)\end{array}$ & $\begin{array}{l}12.0 \\
(1.4)\end{array}$ & $\begin{array}{l}15.3 \\
(1.9)\end{array}$ & $\begin{array}{l}13.8 \\
(1.9)\end{array}$ & $\left|\begin{array}{c}244.5 \\
(195.7)\end{array}\right|$ & $\begin{array}{c}260.3 \\
(205.3)\end{array}$ & $\begin{array}{l}10.5 \\
(4.0)\end{array}$ & $\begin{array}{l}12.0 \\
(3.7)\end{array}$ \\
\hline
\end{tabular}

Table I shows that the VVC procedure provides a significant reduction of the network loss with respect to the initial conditions. For the case of ideal communication (BLER0 and BT0) the percentage reductions are: $62 \%$ and $43 \%$ for TF1 with normal and high load; $14 \%$ and $13 \%$ for TF2 with normal and high load, respectively. Similar reduction are obtained without the local PV voltage control (i.e., $62 \%$ and $46 \%$ for TF1 with normal and high load; $13 \%$ for TF2 with both load levels) or with blocked OLCTs (i.e., $62 \%$ and $44 \%$ for TF 1 with normal and high load; $16 \%$ and $20 \%$ for TF2 with normal and high load), but with average lower voltage values (e.g. for the case of TF1 with high load: $0.99 \mathrm{pu}$ instead of $1.01 \mathrm{pu}$ without local PV voltage control and $0.92 \mathrm{pu}$ with OLCT blocked). Lower voltage values cause lower power consumption by the voltage sensitive loads.

The time needed for the estimation and the assignment of a new reactive power reference value is the time needed to a couple of agents to perform a single compensation cycle. The 
mean value of the packet delay is between $145 \mathrm{~ms}$ and $260 \mathrm{~ms}$ (as shown in Table II, depending on the system and on the assumed level of BLER and BT) and complete compensation cycle requires two exchanges of information between two agents, then each compensation cycle requires on average from $290 \mathrm{~ms}$ to $520 \mathrm{~ms}$ plus the time needed by the local control system of the DG unit to change the reference value that is taken into account by time delay $t_{\text {wait }}$. The computation time of algebraic equations (9) and (10), as well as the evaluation of (11), is assumed to be negligible in the simulations.

For BLER1, the number of compensation cycles reduces and the higher BLER causes both the interruption of incomplete processes and the start of concurrent processes (progressively stopped on the basis of their priority index) due to the loss of packets that carries critical information. Also for BT1, the additional transmissions cause a reduction of the number of compensation cycles and at the same time the increasing of the packets delay.

These effects of BT and BLER levels are illustrated in Fig. 13, which compares the power loss time evolution for TF1 with normal load in different BLER and BT conditions. For the BLER0 - BT0 and BLER0 - BT1, the OLTC operates a first tap change at $22 \mathrm{~s}$ and reaches a final tap equal to -1 . With BLER1 - BT0, the OLTC operates a first tap change to 1 at $22 \mathrm{~s}$, a second tap change to -2 at $32 \mathrm{~s}$ and reaches a final tap equal to -1 at $62 \mathrm{~s}$. With BLER1 - BT1, the OLTC operates a first tap change to -1 at $22 \mathrm{~s}$, a second tap change to -2 at 33 $\mathrm{s}$ and reaches a final tap equal to -1 at $65 \mathrm{~s}$. The increase of the power losses after each tap change is due to the increased consumption of voltage dependent loads. Thanks to the countermeasures described in Section III, the final results with BLER1 and BT1 are similar to those relevant to BLER0 and BT0.

For completeness, Fig. 14 compares the power loss time evolution for TF2 with normal load in different BLER and BT conditions. In all the cases, OLTC1 operates a first tap change at $22 \mathrm{~s}$ and OLTC2 operates at $24 \mathrm{~s}$ and both reach a final tap equal to -1 . Whilst the final results with BLER1 and BT1 are similar to those relevant to BLER0 and BT0, the transient behavior is significant different and, as expected, the fastest decrease of the losses is obtained for the case BLER0-BT0.

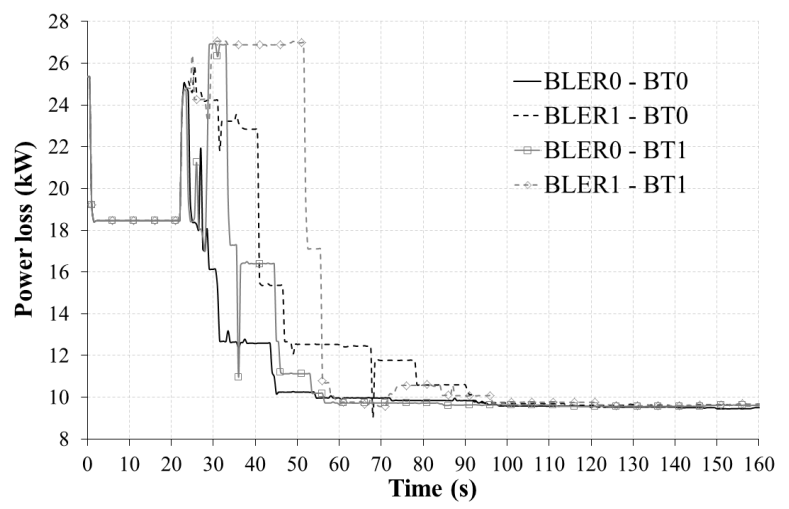

Fig. 13. Power loss variation in TF1 with normal load level for the case of different values of BLER and BT.

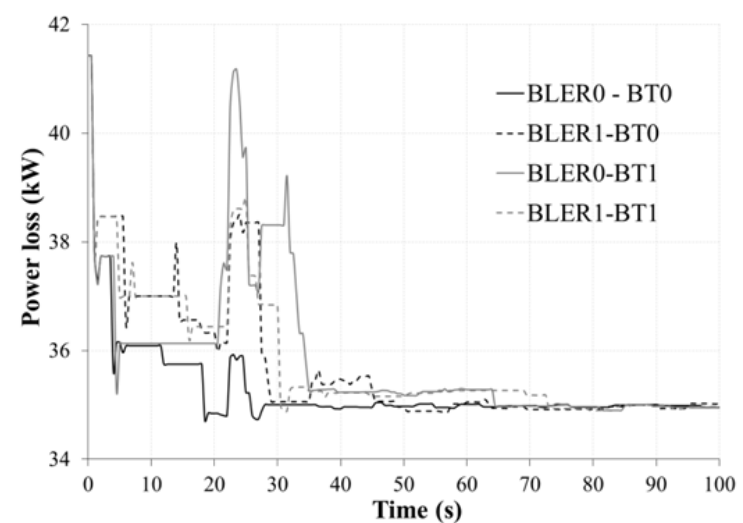

Fig. 14. Power loss variation in TF2 with normal load level for the case of different values of BLER and BT.

\section{CONCLUSIONS}

A secondary VVC procedure based on a MAS approach that uses a shared cellular network has been described and thoroughly analyzed by means of a developed co-simulation platform that represents both communication and power networks. The procedure does not need a detailed state estimation module, since the reactive power flows are estimated by PMUs located at the buses where the PV units that participate to the secondary VVC are connected and at the secondary side of transformers equipped with OLTCs. The action the secondary VVC is adequately coordinated with the local voltage control of both PV units and OLTCs.

The secondary VVC allows a prompt response to variations of the operating conditions of the distribution network due to the intermittently changing power production of PV units. Each compensation cycle requires in general less than few seconds in the simulation tests and the procedure stabilizes in few minutes. Therefore it is fast enough to anticipate the local voltage control of OLTCs and to limit the number of tap changes. Results obtained with and without the analyzed secondary VVC show the benefits in terms of reduction of power losses and voltage profiles along the analyzed networks, i.e., the IEEE 37 and 123-node test feeders.

The procedure includes countermeasures against data loss in the communication network (or in case of unavailability of an agent to receive messages). These countermeasures are based on the activation of concurrent compensation processes controlled by priority indexes. Moreover it includes a spontaneous activation procedure in case of a complete failure of critical communication links. The simulation results show that the procedure has adequate performances also in the presence of significant levels of data loss (represented by the BLER level) and background traffic in the communication links.

\section{ACKNOWLEDGMENT}

The paper is a revised and extended version of contribution [42] presented at the 2015 IEEE Eindhoven PowerTech Conference. We would like to thank the participants, Dr. Franco Fuschini and Dr. Fabio Napolitano for their helpful comments and suggestions. Riverbed modeler software has been used thanks to the Riverbed University Program. EMTP-RV simulation environment has been used in the framework of the Powersys Company Education partnership. 


\section{REFERENCES}

[1] M. E. Baran, H. Hooshyar, Z. Shen, and A. Huang, "Accommodating high PV penetration on distribution feeders," IEEE Trans. Smart Grid, vol. 3, no. 2, pp. 1039-1046, Jun. 2012.

[2] S. Kouro, J. I. Leon, D. Vinnikov, and L. G. Franquelo, "Grid-connected photovoltaic systems: an overview of recent research and emerging PV converter technology," IEEE Ind. Electron. Mag., vol. 9, no. 1, pp. 4761, Mar. 2015.

[3] Y. Yang, H. Wang, and F. Blaabjerg, "Reactive power injection strategies for single-phase photovoltaic systems considering grid requirements," IEEE Trans. Ind. Appl., vol. 50, no. 6, pp. 4065-4076, Nov. 2014.

[4] K. Turitsyn, P. Šulc, S. Backhaus, and M. Chertkov, "Options for control of reactive power by distributed photovoltaic generators," Proc. IEEE, vol. 99, no. 6, pp. 1063-1073, Jun. 2011.

[5] P. Jahangiri and D. C. Aliprantis, "Distributed Volt/VAr control by PV inverters," IEEE Trans. Power Syst., vol. 28, no. 3, pp. 3429-3439, Aug. 2013.

[6] S. Deshmukh, B. Natarajan, and A. Pahwa, "Voltage/VAR control in distribution networks via reactive power injection through distributed generators," IEEE Trans. Smart Grid, vol. 3, no. 3, pp. 1226-1234, Sep. 2012.

[7] H.-G. Yeh, D. F. Gayme, and S. H. Low, "Adaptive VAR control for distribution circuits with photovoltaic generators," IEEE Trans. Power Syst., vol. 27, no. 3, pp. 1656-1663, Aug. 2012.

[8] E. Dall'Anese, S. V. Dhople, and G. B. Giannakis, "Optimal dispatch of photovoltaic inverters in residential distribution systems," IEEE Trans. Sustain. Energy, vol. 5, no. 2, pp. 487-497, Apr. 2014.

[9] S. Jashfar and S. Esmaeili, "Volt/var/THD control in distribution networks considering reactive power capability of solar energy conversion," Int. J. Electr. Power Energy Syst., vol. 60, pp. 221-233, Sep. 2014.

[10] S. Weckx, C. Gonzalez, and J. Driesen, "Combined central and local active and reactive power control of PV inverters," IEEE Trans. Sustain. Energy, vol. 5, no. 3, pp. 776-784, Jul. 2014.

[11] A. Kulmala, S. Repo, and P. Jarventausta, "Coordinated voltage control in distribution networks including several distributed energy resources," IEEE Trans. Smart Grid, vol. 5, no. 4, pp. 2010-2020, 2014.

[12] T. Niknam, M. Zare, and J. Aghaei, "Scenario-based multiobjective Volt/Var control in distribution networks including renewable energy sources," IEEE Trans. Power Deliv., vol. 27, no. 4, pp. 2004-2019, Oct. 2012.

[13] V. Kekatos, G. Wang, A. J. Conejo, and G. B. Giannakis, "Stochastic reactive power management in microgrids with renewables," IEEE Trans. Power Syst., vol. 30, no. 6, pp. 3386-3395, 2015.

[14] M. E. Baran and I. M. El-Markabi, "A multiagent-based dispatching scheme for distributed generators for voltage support on distribution feeders," IEEE Trans. Power Syst., vol. 22, no. 1, pp. 52-59, Feb. 2007.

[15] H. E. Z. Farag and E. F. El-Saadany, "A novel cooperative protocol for distributed voltage control in active distribution systems," IEEE Trans. Power Syst., vol. 28, no. 2, pp. 1-1, 2012.

[16] P. Tenti, A. Costabeber, P. Mattavelli, and D. Trombetti, "Distribution loss minimization by token ring control of power electronic interfaces in residential microgrids," IEEE Trans. Ind. Electron., vol. 59, no. 10, pp. 3817-3826, Oct. 2012.

[17] S. Bolognani, A. Carron, A. Di Vittorio, D. Romeres, L. Schenato, and S. Zampieri, "Distributed multi-hop reactive power compensation in smart micro-grids subject to saturation constraints," in 51st IEEE Conference on Decision and Control, Maui, Hawaii, USA, 2012, no. 257462, pp. 1118-1123.

[18] S. Bolognani and S. Zampieri, "A distributed control strategy for reactive power compensation in smart microgrids," IEEE Trans. Automat. Contr., vol. 58, no. 11, pp. 2818-2833, 2013.

[19] T. Caldognetto, P. Tenti, A. Costabeber, and P. Mattavelli, "Improving microgrid performance by cooperative control of distributed energy sources," IEEE Trans. Ind. Appl., vol. 50, no. 6, pp. 3921-3930, Nov. 2014.

[20] A. Maknouninejad and Z. Qu, "Realizing unified microgrid voltage profile and loss minimization: a cooperative distributed optimization and control approach," IEEE Trans. Smart Grid, vol. 5, no. 4, pp. 16211630, 2014.

[21] W. Zhang, W. Liu, X. Wang, L. Liu, and F. Ferrese, "Distributed multiple agent system based online optimal reactive power control for smart grids," IEEE Trans. Smart Grid, vol. 5, no. 5, pp. 2421-2431,
2014.

[22] J. Aghaei, A. Baharvandi, A. Rabiee, and M. A. Akbari, "Probabilistic PMU Placement in Electric Power Networks: An MILP-Based Multiobjective Model," IEEE Trans. Ind. Informatics, vol. 11, no. 2, pp. 332-341, 2015.

[23] D. Shah, "Gossip algorithms," Found. Trends Netw., vol. 3, no. 1, pp. 1125,2008

[24] G. Sanchez-Ayala, J. R. Aguerc, D. Elizondo, and M. Lelic, "Current trends on applications of PMUs in distribution systems," in 2013 IEEE PES Innovative Smart Grid Technologies Conference (ISGT), 2013, pp. $1-6$.

[25] M. Laughton, "Analysis of unbalanced polyphase networks by the method of phase co-ordinates. Part 1: System representation in phase frame of reference," Proc. Inst. Electr. Eng., vol. 115, no. 8, p. 1163, 1968.

[26] H. Smolleck and R. Shoults, "A straightforward method for incorporating mutually-coupled circuits into the bus admittance matrix using the concept of artificial branches," IEEE Trans. Power Syst., vol. 5, no. 2, pp. 486-491, 1990

[27] T. Chen, M. Chen, T. Inoue, P. Kotas, and E. A. Chebli, "Three-phase cogenerator and transformer models for distribution system analysis," IEEE Trans. Power Deliv., vol. 6, no. 4, pp. 1671-1681, 1991.

[28] J. Peralta, F. de León, and J. Mahseredjian, "Unbalanced multiphase load-flow using a positive-sequence load-flow program," IEEE Trans. Power Syst., vol. 23, no. 2, pp. 469-476, 2008.

[29] A. Borghetti, F. Napolitano, and C. A. Nucci, "Volt/var optimization of unbalanced distribution feeders via mixed integer linear programming," in Proc. of 18th Power Systems Computation Conference, Wroclaw, Poland, 2014, vol. 72, pp. 1-7.

[30] D. J. Hill, T. Liu, and G. Verbic, "Smart grids as distributed learning control," in 2012 IEEE Power and Energy Society General Meeting, 2012, pp. 1-8.

[31] R. Bottura, A. Borghetti, F. Napolitano, and C. A. Nucci, "ICT-power co-simulation platform for the analysis of communication-based volt / Var optimization in distribution feeders," in 5th Innovative Smart Grid Technologies Conference ISGT, Washington, 2014, pp. 1-5.

[32] R. Bottura and A. Borghetti, "Simulation of the volt/var control in distribution feeders by means of a networked multi-agent system," IEEE Trans. Ind. Informatics, vol. 10, no. 4, pp. 2340-2353, 2014.

[33] Q. Yang, J. A. Barria, and T. C. Green, "Communication infrastructures for distributed control of power distribution networks," IEEE Trans. Ind. Informatics, vol. 7, no. 2, pp. 316-327, May 2011.

[34] V. Calderaro, G. Conio, V. Galdi, G. Massa, and A. Piccolo, "Optimal decentralized voltage control for distribution systems with inverter-based distributed generators," IEEE Trans. Power Syst., vol. 29, no. 1, pp. 230241, Jan. 2014.

[35] R. Albarracin and M. Alonso, "Photovoltaic reactive power limits," in 12th International Conference on Environment and Electrical Engineering, 2013, pp. 13-18.

[36] M. Larsson, "Coordination of cascaded tap changers using a fuzzy-rulebased controller," Fuzzy Sets Syst., vol. 102, no. 1, pp. 113-123, Feb. 1999.

[37] R. Bottura, D. Babazadeh, K. Zhu, A. Borghetti, L. Nordstrom, and C. A. Nucci, "SITL and HLA co-simulation platforms: Tools for analysis of the integrated ICT and electric power system," in IEEE 2013 EuroCon, 2013, pp. 918-925.

[38] B. Khodabakhchian, "Modeling on-load tap changers in EMTP-RV," EMTP-RV Newsletter, vol. 1, no. 1, pp. 11-15, 2005.

[39] M. Paolone, A. Borghetti, and C. A. Nucci, "A synchrophasor estimation algorithm for the monitoring of active distribution networks in steady state and transient conditions," in 17th Power Systems Computation Conference (PSCC'11) Stockholm, Sweden, 2011, pp. 22-26.

[40] J. Fuller, J. Solanki, B. Kersting, R. Dugan, and S. J. Carneiro, "IEEE PES distribution test feeders." [Online]. Available: http://www.ewh.ieee.org/soc/pes/dsacom/testfeeders/.

[41] Mishra A.R., Ed., Advanced Cellular Network Planning and Optimisation: $2 G / 2.5 G / 3 G$...Evolution to $4 G$. John Wiley \& Sons, 2007.

[42] R. Bottura, A. Borghetti, M. Barbiroli, and C. A. Nucci, "Reactive power control of photovoltaic units over wireless cellular networks," in 2015 IEEE Eindhoven PowerTech Conference, Eindhoven, 2015, pp. 1-7.

Alberto Borghetti (M'97-SM'03-F'15) was born in Cesena, Italy, in 1967. He graduated (with honors) in electrical engineering from the University of Bologna, Italy, in 1992. Since then he has been working with the power system group of the same University, where he was appointed Researcher in 
1994 and Associate Professor in 2004. His research and teaching activities are in the areas of power system analysis, with particular reference to voltage collapse, power system restoration after blackouts, electromagnetic transients due to lightning, optimal generation scheduling and distribution system operation. Currently he serves as an Editor of IEEE Trans. on Smart Grid and is on the editorial board of Electric Power System Research.

Riccardo Bottura (S'13) was born in Ostiglia, Italy, in 1986. He received the M.S. degree in telecommunication engineering in 2011 and the Ph.D. degree in electrical engineering in 2015 both from the University of Bologna, Italy. His research interests include the analysis and co-simulation of networked control systems applied to electric power distribution networks.

Marina Barbiroli received the Laurea degree in electronic engineering, and the Ph.D. degree in computer science and electronic engineering from the University of Bologna, Italy, in 1995 and 2000, respectively, where she serves as Researcher since 2001. Her research and teach activities are related to the investigation of propagation mechanism at different frequencies and wideband channel models for mobile communications systems. Dr. Barbiroli's research activity includes the participation to the European research and cooperation programs (COST 259, COST 273, COST 2100, IC004, IRACON).
Carlo Alberto Nucci (M'91-SM'02-F'07) is full professor and head of the Power Systems Laboratory of the Department of Electrical, Electronic and Information Engineering 'Guglielmo Marconi' of the University of Bologna, Italy. $\mathrm{He}$ is author or co-author of over 300 scientific papers published on peer-reviewed journals or on proceedings of international conferences, of six book chapters edited by IEE, IET (two), Kluwer, Rumanian Academy of Science and WIT press and of a couple of IEEE Standards and some CIGRE technical brochures. He is a Fellow of the IEEE and of the IET, CIGRE honorary member and has received some best paper/technical international awards, including the CIGRE Technical Committee Award and the ICLP Golde Award. From January 2006 to September 2012 he has served as Chairman of Cigré Study Committee C4 'System Technical Performance'. Since January 2010 he is serving as Editor in Chief of the Electric Power Systems Research journal, Elsevier. Prof. Nucci is doctor honoris causa of the University Politehnica of Bucharest and corresponding member of the Bologna Science Academy. He has served as president of the Italian Group of University Professors of Electrical Power Systems (GUSEE) from 2012 to 2015. He is an advisor of the Global Resource Management Program of Doshisha University, Kyoto, supported by the Japanese Ministry of Education and Science. He has been serving as member of the EU Smart City Stakeholder Platform since 2013, and since 2014 is representing PES in the IEEE Smart City Initiatives Program. 